\title{
Physical and Chemical Properties of the Lipase of Thermophilic Fungus Humicola lanuginosa S-38
}

\author{
Wen-Hsiung LIU,* Teruhiko BePPU and Kei ARImA \\ Department of Agricultural Chemistry, The University of Tokyo, Bunkyo-ku, Tokyo
}

Received April 18, 1973

\begin{abstract}
Some physical and chemical properties of the extracellular lipase from the thermophilic fungus, Humicola lanuginosa $S-38$, were investigated. The results were as follows: Sedimentation coefficient was $2.4 \times 10^{-13}(\mathrm{~cm} \cdot \mathrm{g} / \mathrm{sec} \cdot$ dyne $)$; diffusion coefficient was $8.8 \times 10^{-i}$ $\left(\mathrm{cm}^{2} / \mathrm{sec}\right)$; and frictional coefficient was 1.22 . Molecular weight was $27,500 \pm 500$ and $a-$ helix content was $18.9 \%$. The number of amino acid residues contained in 1 mole of protein of Humicola lipase was 224. Sugar and lipid were not detected. The effect of calcium ion and denaturing reagents, such as urea, sodium dodecyl sulfate and dithiothreitol, on the thermostability of Humicola lipase was examined. It was concluded that the thermostability of Humicola lipase was not influenced by protective cofactors but was attributable to the enzyme itself. Some properties of enzyme structure which were concerned with the thermostability of Humicola lipase are also discussed.
\end{abstract}

The thermostable mechanism of the thermophilic enzyme has evoked the considerable interest of many investigators during the past two decades. Manning, Campbell and Foster $^{2}$ reported that the thermostability of $a$-amylase from Bacillus stearothermophilus was due to the characteristic less-ordered structure of the enzyme itself. Using $a$ amylases from other strains of Bacillus stearothermophilus other reported ${ }^{3,4)}$ that these enzymes existed as a globular structure as those of many mesophilic $a$-amylase. They pointed out that a slight excess of amino acids with hydrophobic side chains and the presence of calcium ion played an important role in the thermostability of thermophilic $a$-amylase molecules. Thermostable protease from Bacillus thermoproteolyticus has been reported to be a compact globular protein by Ohta et al. ${ }^{5)}$ It was concluded that the thermostable enzyme from thermophiles was not always related to the random structure of the enzyme as reported by Manning $e t$ al.

+ Studies on the Lipase of Thermophilic Fungus Humicola lanuginosa. Part VI. For Part V see Reference 1).

* Present address: Laboratory of Fermentation, Department of Agricultural Chemistry, National Taiwan University, Taipei, Taiwan, Republic of China.
It is well known that lipase has the unusual property of being functional only at an oil/ water interface. It has been postulated that the ability of lipase to act on the triglyceride at an oil/water interface resulted from the relative stability of its characteristic protein structure at an oil/water interface. Unfortunately, owing to the unstable property of lipase, homogeneous lipase was obtained only in a few case and the information on the characteristic structure of lipase is still very limited.

In the previous report ${ }^{6)}$ the lipase produced by a thermophilic fungus, Humicola lanuginosa $S-38$, was found to be much more thermostable than those of mesophiles. The thermostability of this enzyme provides a great advantages in investigating the structure of lipase. The present report is concerned with some physical and chemical properties of this thermostable lipase.

\section{MATERIALS AND METHODS}

Preparation of enzyme. The enzyme used in this study was prepared as described previously ${ }^{6}$ and confirmed to be homogeneous with disc electrophoresis and ultracentrifugal analyses. 
Estimation of lipase activity. Lipase activity was estimated by the olive oil emulsion method as described preivously. ${ }^{71} \quad$ One unit of lipase activity was defined as the amount which liberated $1 \mu$ mole of free fatty acid per minute at $45^{\circ} \mathrm{C}$ and $\mathrm{pH} 8.0$.

Ultracentrifugal sedimentation rate and equilibrium analyses. Analytical ultracentrifugation was carried out with a Hitachi analytical ultracentrifuge UCA-1 A. Synthetic boundary cell was used in the sedimentation rate analysis. The sedimentation equilibrium analysis was performed by Archibald's method ${ }^{8 /}$ using a standard cell and a synthetic boundary cell with the Schlieren optical system.

Molecular weight determination (Andrews' method). ${ }^{91}$ Sephadex G-100 was equilibrated with $0.05 \mathrm{M}$ Tris$\mathrm{HCl}$ buffer $(\mathrm{pH} 8.0)$ and packed into a column of dimension $2.2 \mathrm{~cm} \times 48 \mathrm{~cm}$. The blue dextran was used as a void volume marker and bovine albumin (M.W. 67,000), egg albumin (M.W. 45,000), a-chymotrypsinogen (M.W. 25,000) and myoglobin (M.W. 15,000) were also used as standards of molecular weight. The Humicola lipase was applied to the column with these markers and eluted with the equilibrating buffer. The amount of blue dextran and other markers were measured spectrophotometrically at 600 and $280 \mathrm{~m} \mu$ respectively.

Circular dichroism analysis. The measurement of the circular dichroism at $210 \sim 250 \mathrm{~m} \mu$ was performed using a Jasco ORD/UV-5 modified by a circular dichroism attachment (Japan Spectroscopic Co., Ltd.). Molecular ellipticity $[\theta]$ was obtained by the equation, $[\theta]=3,300\left(E_{l}-E_{r}\right)$, where $\left(E_{l}-E_{r}\right)$ is the difference between the molar extinction coefficients for left and right circularly polarized light. In the calculation of $\left(E_{l}-E_{r}\right)$, the mean residue weight was used instead of molecular weight. An apparent content of righthanded $a$-helix was calculated as follows: $a$-helix content $=-[\theta]_{222} / 400,000 \times 100$. $^{3)}$

Amino acid analysis. Amino acid composition of the enzyme was determined with a JLC-5 AH type automatic amino acid analyzer (Japan Electric Co, Ltd.). Hydrolysis was performed with $6 \mathrm{M} \mathrm{HCl}$ at $110^{\circ} \mathrm{C}$ for 24,48 and $72 \mathrm{hr}$, respectively. The tryptophan content of the enzyme was determined by the spectrophotometric method.10 ${ }^{10}$ Cystine and cysteine were determined as cysteic acid after performic acid oxidation and hydrolysis of the enzymes." ${ }^{11}$

Partial specific volume. The partial specific volume of the enzyme was computed from the specific volume of constituent amino acid residues. ${ }^{12}$ )

Elementary analysis. The enzyme was dialyzed against distilled water, then dried until the weight became constant. Hydrogen, carbon and nitrogen content of the enzyme were determined by microanalysis.

Carbohydrate analysis. The hexose and hexosamine content in the enzyme were determined respectively by the phenol-sulfuric acid method ${ }^{13)}$ and the ElsonMorgan method. ${ }^{14}$

Lipid analysis. The enzyme solution containing $0.1 \% \mathrm{HCl}$ was extracted at $65^{\circ} \mathrm{C}$ for $30 \mathrm{~min}$ with a chloroform: methanol mixture $(1: 1, \mathrm{v} / \mathrm{v})$. The upper extracted layer was dried up using a rotary evaporator. The quantitative analysis of the dried sample was performed by thin-layer chromatography. The development solvent used to detect the lipid was a petroleum ether: ethyl ether: acetic acid mixture $(80: 30: 1, \mathrm{v} / \mathrm{v})$ and $10.0 \%$ of phosphorus molybdate in $10.0 \%$ ethyl alcohol.

Chemicals. Chemicals with a reagent grade were obtained from Tokyo Kasei, Kogyo Co., Ltđ. and Kokusan Chemical Work, Ltd.

\section{RESULTS}

\section{Sedimentation coefficient}

The enzyme was dissolved in $0.05 \mathrm{M}$ Tris$\mathrm{HCl}$ buffer $(\mathrm{pH} 8.0)$ and adjusted to three different concentrations $(1.2 \%, 0.75 \%$ and $0.35 \%$ ). The enzyme solutions were employed for the sedimentation rate analysis using a synthetic boundary cell. The sedimentation patterns are shown in Fig. 1. The sedimentation coefficients at various concentrations are plotted in Fig. 2. The straight line obtained was extrapolated to zero concentration. Thus, $s_{20, \mathrm{w}}^{0}$ was estimated to be $2.4 \times 10^{-13}$ $(\mathrm{cm} \cdot \mathrm{g} / \mathrm{sec} \cdot$ dyne $)$.

\section{Diffusion coefficient}

An $0.8 \%$ enzyme solution was used for the sedimentation equilibrium analysis using a standard cell and a synthetic boundary cell. The sedimentation equilibrium patterns are shown in Fig. 3. The value of the diffusion coefficient at $20^{\circ} \mathrm{C}$ was calculated at $8.8 \times 10^{-7}$ $\left(\mathrm{cm}^{2} / \mathrm{sec}\right)$ and the molecular weight was estimated to be 27,300 by Archibald's method. The frictional coefficient was 1.22. During these estimations, the partial specific volume of the Humicola lipase was $0.76 \mathrm{ml} / \mathrm{g}$ which 


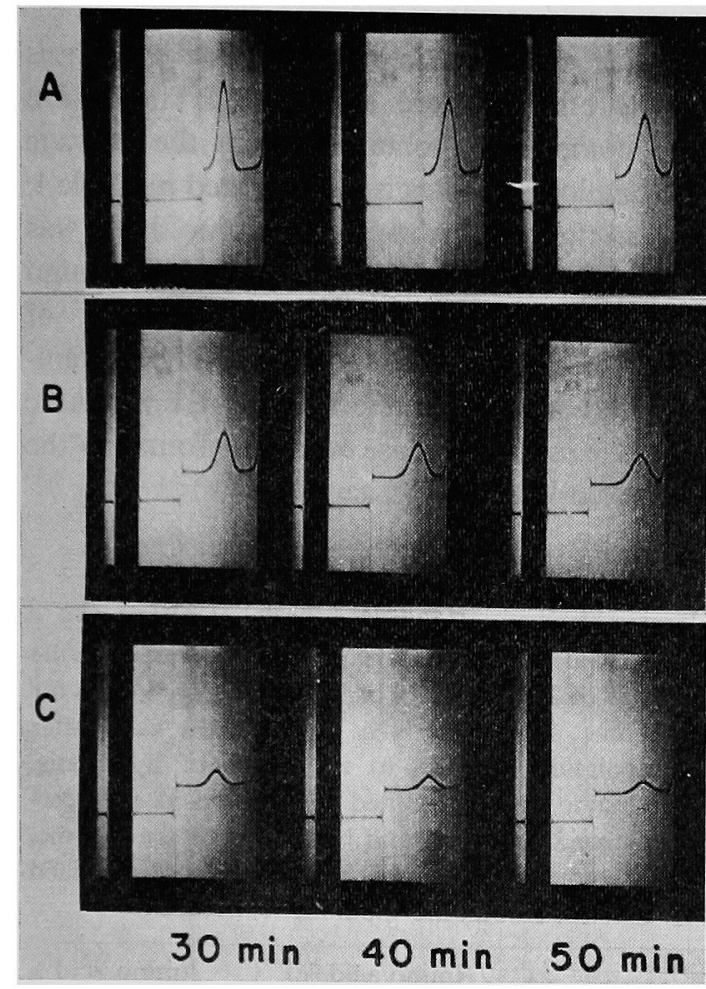

FIG. 1. Ultracentrifuge Patterns of Humicola Lipase. Enzyme concentration. A, $1.2 \% ; \mathrm{B}, 0.75 \%$, C, $0.35 \%$. The $0.05 \mathrm{M}$ Tris- $\mathrm{HCl}$ buffer ( $\mathrm{pH} 8.0$ ) contained $0.1 \mathrm{M} \mathrm{KCl}$. Synthetic boundary cell was used, $60,000 \mathrm{rpm}, 25^{\circ} \mathrm{C}$.

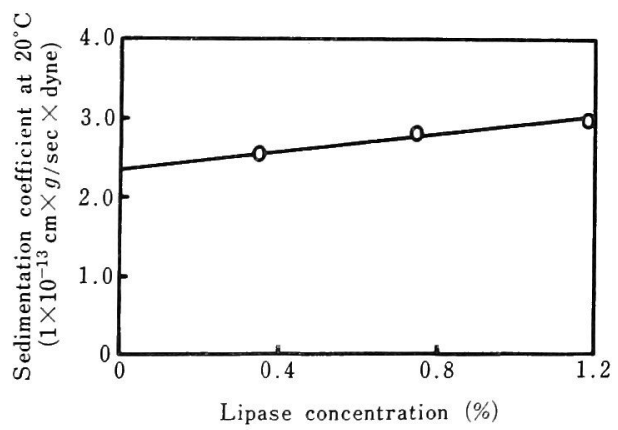

FIG. 2. Determination of Sedimentation Coefficient of Humicola Lipase.

was computed from the specific volume of constituent amino acid residues.

Estimation of the molecular weight by Sephadex G-100 column chromatography

The detailed procedures are described in MATERIALS AND METHODS. As shown

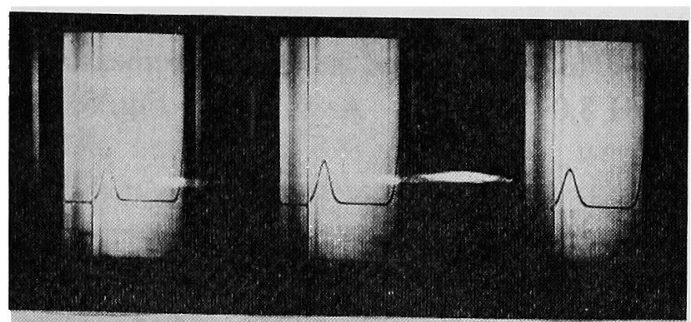

\section{Synthetic boundary cell}

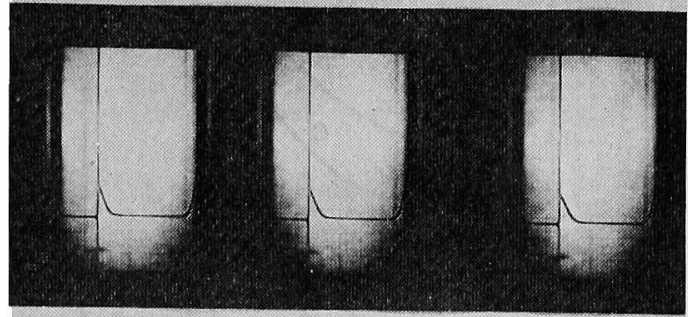

Standard cell

Fig. 3. Sedimentation Equilibrium Patterns of Humicola Lipase.

Enzyme concentration $=0.8 \%, 0.05 \mathrm{M}$ Tris- $\mathrm{HCl}$ buffer (pH 8.0) contained $0.1 \mathrm{M} \mathrm{KCl} ; 13,000 \mathrm{rpm}, 25^{\circ} \mathrm{C}$. Photographed at $10 \mathrm{~min}$ intervals.

in Fig. 4, the molecular weight of the Humicola lipase was estimated to be around 27,500.

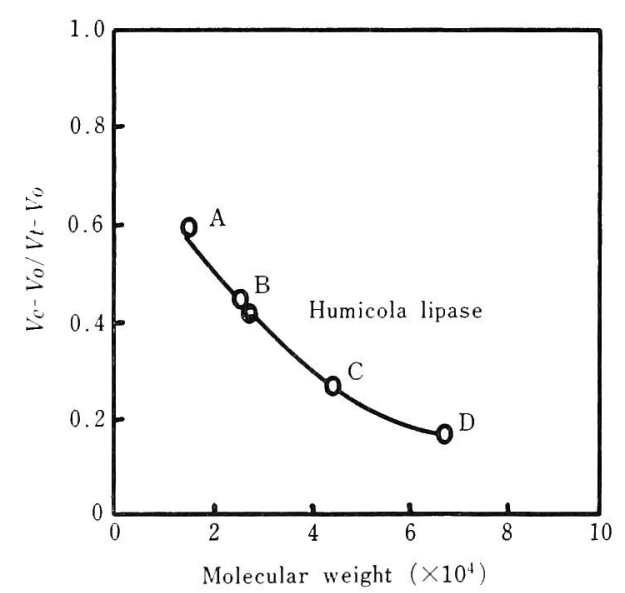

FIg. 4. Estimation of the Molecular Weight of Humicola Lipase by Sephadex G-100 Column Chromatography.

A, myoglobin; B, a-chymotrypsinogen; C, egg albumin; D, bovine albumin; Vo; void volume, Vt, total volume of Sephadex column; Ve, elution volume.

\section{Circular dichroism analysis}

The circular dichroism (CD) spectra in the 
$210 \sim 250 \mathrm{~m} \mu$ region for the enzyme in the native and denatured states were measured at $\mathrm{pH} 8.0$ and $25^{\circ} \mathrm{C}$. As shown in Fig. 5, the

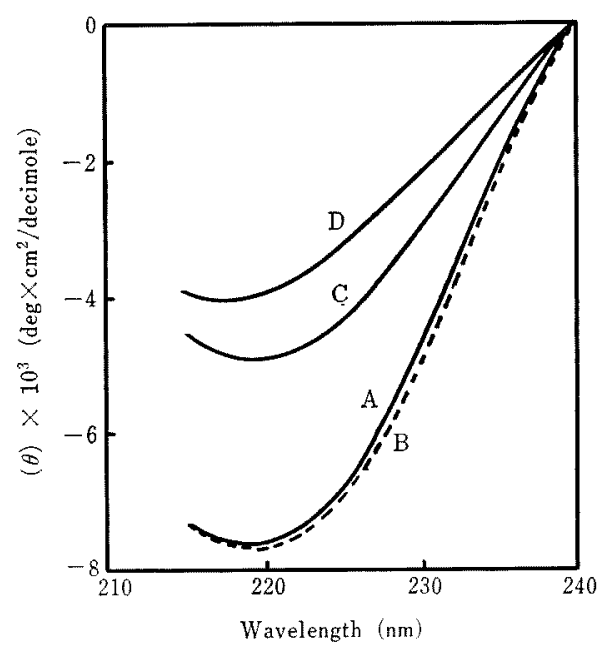

FIG. 5. Effect of Urea, SDS and Heat-treatment on the Circular Dichroism Spectrum of Humicola Lipase. A, control; B, added $1 \times 10^{-2} \mathrm{M}$ sodium dodecyl sulfate; $\mathrm{C}$, added $8 \mathrm{M}$ urea; $\mathrm{D}$, heated at $80^{\circ} \mathrm{C}$ for $20 \mathrm{~min}$.

$C D$ spectrum of the native lipase showed a trough at $220 \sim 222 \mathrm{~m} \mu$. This trough position is characteristic of proteins having a $a$-helix structure. The molecular ellipticity at $222 \mathrm{~m} u,[\theta]_{292}$ for the Humicola lipase was estimated to be $-7.56 \times 10^{3}\left(\mathrm{deg} \cdot \mathrm{cm}^{2} / \mathrm{deci}-\right.$ mole). The content of $a$-helix in the enzyme was calculated as 18.9 . In the presence of $10^{-*} \mathrm{M}$ sodium dodecyl sulfate at $\mathrm{pH} 8.0$, the $\mathrm{CD}$ spectrum of enzyme at room temperature showed a similar pattern to that of the native one. On the contrary, on heating at $80^{\circ} \mathrm{C}$ for $20 \mathrm{~min}$ or in the presence of $8 \mathrm{M}$ urea, the CD spectra of the enzyme showed a different patterns from the native one. In the presence of $8 \mathrm{M}$ urea, the negative value of $[\theta]_{222}$ decreased from $-7.56 \times 10^{3}$ to $-4.8 \times 10^{3}$ On heating at $80^{\circ} \mathrm{C}$ for $20 \mathrm{~min}$, the negative value of $[\theta]_{222}$ decreased further to $-4.0 \times 10^{3}$. From these results, it was apparent that the $a$-helix structure of enzyme was changed by the $8 \mathrm{M}$ urea or the heat treatment.

\section{Amino acid composition}

Three different time periods for hydrolysis of the enzyme were employed. The amino acid composition obtained from the average of three hydrolysates is summarized in Table I. The content of hydrophobic amino acids was higher than the content of hydrophilic amino acids. The abnormally high contents of tyrosine and proline which had been emphasized as a characteristic of thermophilic protease and $a$-amylase were not found in the Humicola lipase.

\section{Table I. Amino Acid Composition of the Humicola LIPASE}

The values of the amino acid were obtained from the average of 24,48 and $72 \mathrm{hr}$ hydrolysates. Values for threonine, serine and $\mathrm{NH}_{3}$ represent the value after extrapolation of each to zero time of hydrolysis. 1/2-Cystine was determined as cysteic acid after performic acid oxidation and hydrolysis of the enzyme. The tryptophan content of the enzyme was determined by spectrophotometric method.

\begin{tabular}{lcc}
\hline Amino acid & $\begin{array}{c}\text { Amino acid }(\mathrm{g}) \\
\text { per } 100 \mathrm{~g} \text { of } \\
\text { protein }\end{array}$ & $\begin{array}{c}\text { Amino acid } \\
\text { residues per } \\
\text { molecule }\end{array}$ \\
\hline Arg & 7.27 & 11 \\
Lys & 3.55 & 7 \\
His & 3.47 & 6 \\
Asp & 11.27 & 23 \\
Glu & 7.39 & 12 \\
Ser & 6.60 & 17 \\
Thr & 7.50 & 19 \\
Tyr & 3.68 & 6 \\
Gly & 6.71 & 25 \\
Ala & 6.02 & 19 \\
Val & 6.70 & 16 \\
Ile & 6.03 & 13 \\
Leu & 7.85 & 17 \\
Pro & 4.33 & 10 \\
Phe & 7.62 & 13 \\
Trp & 1.83 & 3 \\
Met & 0.24 & 1 \\
1/2-Cys & 2.80 & 6 \\
NH & 1.40 & 224 \\
Total & & \\
\hline
\end{tabular}

Elementary analysis and absence of carbohydrate and lipid

Elementary analysis of the purified lipase showed $13.7 \%$ of nitrogen, $48.7 \%$ of carbon and $6.5 \%$ of hydrogen. Hexose and hexos- 
amine were not detected in the purified lipase by the phenol-sulfuric acid method or the Elson-Morgan method. Lipid was not detected according to the quantitative analysis by thin-layer chromatography after extraction of the purified lipase with a chloroform and methanol mixture at $65^{\circ} \mathrm{C}$ for $30 \mathrm{~min}$.

Effect of denaturing reagents on the thermostability

As shown in Fig. 6, on heating at $80^{\circ} \mathrm{C}$ for $20 \mathrm{~min}$ not only was the protein structure

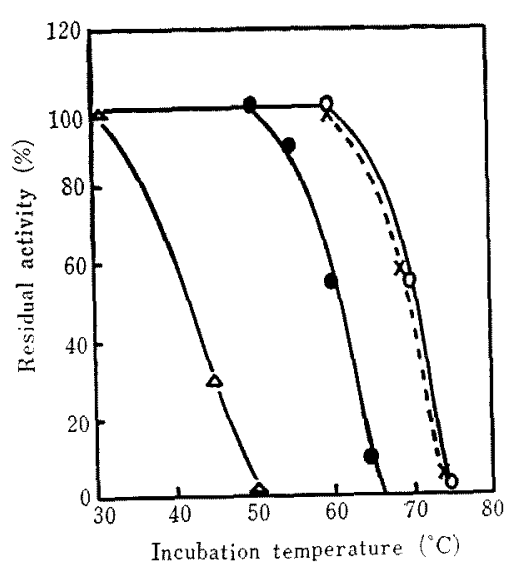

FIG. 6. Effect of Calcium Ion and Denaturing Reagents on the Thermostability of Humicola Lipase. O. control; $\leadsto$, added $1 \times 10^{-2} \mathrm{M}$ calcium ion; added $8 \mathrm{M}$ urea; $\triangle$, added $1 \times 10^{-2} \mathrm{M}$ sodium dodecyl sulfate. Incubation condition: pH $8.0,20 \mathrm{~min}$.

changed but the lipase activity was also completely inactivated. However, after the enzyme was treated with $8 \mathrm{~m}$ urea at room temperature for $20 \mathrm{~min}$, the full lipase activity returned providing that the urea concentration was reduced by dilution. This indicated that the denaturing action of $8 \mathrm{~m}$ urea on the lipase at room temperature was a reversible reaction. But an interesting feature was that the simultaneous action of temperature and urea caused a marked denaturation while the native lipase was stable on heating alone. Therefore, it was clear that the effect of urea on the lipase was to lower the denaturation temperature. To lower the denaturation temperature, sodium dodecyl sulfate was more effective than $8 \mathrm{~m}$ urea. On the other hand, calcium ion did not enchance the thermostability of native lipase.

The activity of Humicola lipase was not affected by treatment with a sulfhydryl reducing agent, dithiothreitol, at room temperature but the thermostability of Humicola lipase was lowered. In the presence of $8 \mathrm{M}$ urea and sulfhydryl reducing agent, the heat inactivation of the enzyme was accelerated (Fig. 7).

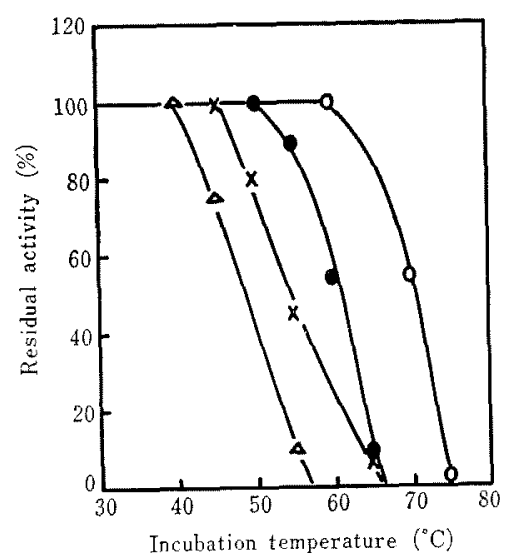

Frg. 7. Effect of Sulfhydryl Reducing and Denaturing Reagents on the Thermostability of Humicola Lipase.

0 , control; $\bullet$, added $8 \mathrm{M}$ urea; $\times$, added $1 \times 10^{-2} \mathrm{M}$ dithiothreitol; $\triangle$, added $8 \mathrm{M}$ urea and $1 \times 10^{-2} \mathrm{M}$ dithiothreitol. Incubation condition: $\mathrm{pH} 8.0,20 \mathrm{~min}$.

\section{DISCUSSION}

Since Manning et al. ${ }^{2}$ reported that the thermostability of the thermophilic $a$-amylase was due to the characteristic structure of the protein itself, two explanations have been offered about the structure of thermostable protein. The first was that the enzyme existed as a randomly coiled structure and the second explanation was that enzyme existed as a rigid structure. It was pointed out that the randomly coiled structure of thermophilic $a$-amylase was due to the high proline content ${ }^{15}$, and that the rigid structure of thermophilic protease resulted from the abundance of amino acids with hydrophobic side chains and the high tyrosine content." Although the ratio of the content of hydrophobic amino acids in 
the Humicola lipase was similar to those of thermophilic $a$-amylase and protease, an abnormally high content of proline or tyrosine was not found in the Humicola lipase (Table I). Meanwhile, the a-helix content of Humicola lipase was found to be $18.9 \%$ which was similar to that of mesophilic $a$-amylase. Thus, the explanation of thermostability by Campbell $^{2,15)}$ and $\mathrm{Ohta}^{5,10)}$ does not appear satisfactory in the case of Humicola lipase.

It was reported ${ }^{3,4,17}$ that calcium ion played an important role in the thermostability of both thermophilic $a$-amylase and protease. As shown in Fig. 6, the thermostability of Humicola lipase was not promoted by the addition of calcium ion. On the other hand, it was confirmed that the lipase activity was not affected by dialysis or EDTA treatment. The thermostability of Humicola lipase was not obviously related to protective cofactors and was attributable only to the enzyme itself.

It was pointed out ${ }^{18)}$ that the content of hydrophobic amino acids in lipase protein was higher than that of other hydrolase and those proteins which were not related to lipid. On general principles, such a high content of hydrophobic amino acids in the enzyme molecule could provide a compact structure which is not easily denatured by a change in the external environment. However, the composition of hydrophobic amino acids in thermophilic enzymes was diverse, and lipases so far examined were always thermo-unstable. These facts indicate that the higher content of hydrophobic amino acids in the lipolytic enzyme was not sufficient to make them thermostable. It is obvious that the composition or arrangement of hydrophobic amino acids in the enzyme molecule was more important than the content alone.

As shown in Fig. 5, at room temperature, the addition of $8 \mathrm{M}$ urea induced a distinct change of the $\mathrm{CD}$ spectrum of Humicola lipase indicating a considerable alteration in the enzyme structure. However, after the $8 \mathrm{M}$ urea treatment at $50^{\circ} \mathrm{C}$ for $20 \mathrm{~min}$, the lipase activity was not affected providing that the urea concentration was reduced by dilution
(Fig. 6). Such extreme stability along with reversibility of the enzyme against conformational change might be due to the strong attractive forces of the hydrophobic structure in the enzyme molecule. Therefore, it is suggested that such a hydrophobic structure might be concerned with the stability of Humicola lipase against changes in the external environment such as denaturing reagents and temperature.

The activity of Humicola lipase was not affected by treatment with sulf hydryl reducing agent, dithiothreitol, at room temperature but it rendered the enzyme more susceptible to heat inactivation. Furthermore, the heat inactivation of the enzyme was accelerated by the addition of $8 \mathrm{M}$ urea (Fig. 7). According to the results of amino acid analysis, Humicola lipase contained six half-cystine residues per enzyme molecule (Table I). However, no free sulfhydryl group was detected in a spectrophotometric study with $p$-chloromercuribenzoate in the presence or absence of $8 \mathrm{M}$ urea, ${ }^{19}$ ? which suggested that these half-cystine residues might exist as disulfide linkages in the enzyme molecule. In addition to hydrophobic structure, these disulfide linkages might play an important role in maintaining the enzyme structure against thermal denaturation.

Acknowledgement. Authors are deeply grateful to Drs. Makari Yamasaki, Takeshi Uozumi and Takashi Saiki, Department of Agricultural Chemistry, the University of Tokyo, for many valuable discussions. The skilled technical assistance of Dr. Tairo Oshima, Mitsubishi Kasei Institute of Life Science, Tokyo; Miss Keiko Tomita, the Institute of Applied Microbiology, the University of Tokyo; and Mr. Hidemasa Hidaka, Meiji Seika Co., Ltđ, are also gratefully acknowledged. They performed respectively the circular dichroism analysis; the ultracentrifugal analysis; and the amino acid analysis.

\section{REFERENCES}

1) W.-H. Liu, T. Beppu and K. Arima, Agr. Biol. Chem., 37, 2493 (1973).

2) G. B. Manning, L. L. Campbell and R. J. Foster, J. Biol. Chem., 236, 2958 (1961).

3) K. Ogasahara, A. Imanishi and T. Isemura, $J$. Biochem., 67, 65 (1970).

4) S. L. Pfueller and W. H. Elliott, J. Biol. Chem., 
244, 48 (1969).

5) Y. Ohta, Y. Ogura and A. Wada, J. Biol. Chem., 241, 5919 (1966).

6) W.-H. Liu, T. Beppu and K. Arima, Agr. Biol. Chem., 37, 157 (1973).

7) K. Arima, W.-H. Liu and T. Beppu, ibid., 36, 1913 (1972).

8) H. K. Schachman, "Method of Enzymology," Vol. IV, ed. by S. P. Colowick and N. O. Kaplan, Academic Press Inc., New York, N. Y., 1957, p. 32.

9) P. Andrew, Biochem. J., 91, 222 (1964).

10) W. L. Beneze and K. Schmid, Anal. Chem., 29, 1193 (1957).
11) C. H. W. Hirs, J. Biol. Chem., 219, 611 (1956).

12) T. Isemura and S. Fujita, J. Biochem., 44, 797 (1957).

13) M. Dubosis, K. A. Gilles, J. K. Hamilton, P. A. Rebers and F. Smith, Anal. Chem., 28, 350 (1956).

14) L. A. Elson and W. T. L. Morgan, Biochem. J., 27, 1824 (1933).

15) L. L. Campbell and G. B. Manning, J. Biol. Chem., 236, 2962 (1961).

16) Y. Ohta, ibid., 242, 509 (1967).

17) S. Endo, J. Ferment. Tech., 40, 346 (1962).

18) N. Tomizuka, Y. Ota and K. Yamada, $A g r$. Biol. Chem., 30, 1090 (1966).

19) P. D. Boyer, J. Amer. Chem. Soc., 76, 4331 (1954). 